\title{
Goodness-of-Fit Ethics for Multicultural Research
}

\author{
Celia B. Fisher \\ Kathleen RagsDale
}

All medical and public-health researchers would like a magic bullet that would make research undeniably ethical. But there is no magic bullet. There is only the complex and difficult process of linking research in resource-poor settings to the services demanded by poor people.

-Paul Farmer, "Can Transnational Research Be Ethical in the Developing World?"

I $\mathrm{n}$ this chapter, we discuss the dynamic nature of ethnic minority status and the unique challenges and opportunities this concept presents for scientists engaged in the ethical practice of research. Next, we discuss goodness-of-fit ethics (GFE) as a model for ethics-in-science decision making (Fisher, 2004). We then discuss the concept of co-learning and its role in the process of developing GFE, using case studies to illustrate particular points. We close with a discussion of "doing good well" as a concept that involves reframing traditional power dynamics associated with behavioral science in such a way that individual participants, their communities, and researchers are actively involved in a dynamic process of mutual accommodation that also meets the requirements of the scientific process.

\section{THE DYNAMIC \\ NATURE OF ETHNICITY \\ AND MINORITY STATUS}

Ethnicity as a research variable is a dynamic construct continuously challenged, expanded, and revised within an ever changing sociopolitical landscape. This fluid definitional environment requires cultural and ethical competence to ensure the responsible conduct of research with ethnic minority populations in the United States and abroad. Ethnic minority populations are challenging venues within 
which to conduct research for reasons including historical and contemporary stigmatization, cultural attitudes regarding individual autonomy and communal responsibility, within-group cultural variation, immigration history, language, acculturation-related issues, and multiethnic heritage (Fisher, Jackson, \& Villarruel, 1997). Such challenges highlight the question, "What is ethnicity?" In this chapter we define ethnicity as a collective identity based on the shared cultural heritage of a social group. Typical markers of ethnicity, which vary across groups, include dress, language, foodways, religious and traditional practices, common ancestry, and/or geographic origin (Ragsdale, 2004). We draw an important distinction between the concept of ethnicity and the concept of race, in that race is not a scientific construct but a social construct used to classify individuals based on phenotypic variation (Fisher et al., 1997; Gould, 1981). We also draw a distinction between ethnic status and minority status. Whereas minority status is often conferred on a subordinated or marginalized social group by the dominant culture, ethnic status is a claim made by a particular collective body to a designated social identity (Eller, 1999; Ragsdale, 2004). In the next section, we draw on examples from the United States in order to illustrate the fluidity of ethnicity and minority status.

\section{Contemporary Prejudice and Changing Demographics in the United States}

Members of minority and ethnically marginalized populations experience multiple incidents of actual and perceived discrimination on an individual level from peers and on an institutional level from health care providers, educators, shopkeepers, social service providers, educators, police and security personnel, and others (Chun, 1995;
Demo \& Hughes, 1990; Essed, 1991; Fisher, Wallace, \& Fenton, 2000; Gaertner \& Dovidio, 1986). The contemporary experience of institutionalized discrimination within the United States is deeply embedded within the historical groundwork of European conquest. Long before the United States existed as such, it was a multiethnic society. Individual members of indigenous populations conquered by Spanish, French, and English colonizers were assimilated into the dominant culture with varying "success," often through institutions such as slavery, the church, intermarriage, and educational systems. Later, enslaved peoples of African descent were conscripted as field labor for agricultural exports. Still later, poverty-stricken foreign nationals (such as Asian workers imported to build the transatlantic rail system) were allowed into the United States as a form of cheap labor during the industrial revolution. By the end of the 20th century, the experience of transnational integration had accelerated with the expansion of the global economy, communication technologies, and transportation. In the contemporary United States, economic migrants from Mexico and other Central American countries perform the manual labor that many U.S. nationals will not. In addition, political refugees from around the world are granted asylum in the United States, and lotteries allow other foreign nationals to immigrate to the country.

Although members of diverse ethnic groups may have shared experiences with historical and contemporary racism, groups may experience discrimination differently. This can be traced back to earlier U.S. political and social policies regarding peoples of non-European ethnicity, as well as issues of resistance and accommodation to dominant U.S. culture (Dublin, 1996; Gould, 1981; Ragsdale, 2004). For example, Cubans arrived en masse to the United States as political refugees beginning in the early 
1960s. Those Cubans who settled in Miami, Florida, developed an enclave community that wields considerable political and economic dominance in Miami-Dade County (Portes \& Stepick, 1993). In contrast, Haitians who arrived en masse to the United States as political refugees in the early 1980 s have continued to experience social, economic, and political marginalization in Miami (Stepick \& Foner, 1998; Stepick, Grenier, Castro, \& Dunn, 2003). The divergence in discrimination experienced across ethnic groups can often be attributed to racial/ethnic stereotyping, which can be both positive and negative. For example, a highstatus African national who has recently migrated to the United States may be confronted with racial/ethnic prejudice-and an accompanying loss of social statusbased solely on ascribed characteristics that members of the dominant culture associate with his or her skin tone. The African national's first experiences with racial discrimination in the United States may be a cause of intense culture shock, especially if this experience was previously unknown to the person (see Mathabane, 1990; Ogbaa, 2003). Publicized threats to members of one's cultural group can also result in personal anxiety. The racial profiling that resulted in the 1999 police slaying of Amadou Diallo, an unarmed Guinean immigrant, exemplified the distal effects of institutional racism (Diallo, 2003). On the other hand, the generally positive stereotyping of Asians immigrants within the United States has been associated with academic achievement among some Asian youth in the U.S. educational system (Lowe, 1996).

Other factors that can mediate differential experiences of discrimination include characteristics unique to a particular ethnic enclave, such as internalized cultural attitudes that shape beliefs, decision making, and behavior (Ogbaa, 2003; Ragsdale, 2004). Despite the divergence in discrimination that ethnic groups often experience, they also may share many unique similarities as minority populations operating within a dominant society. These can include issues related to acculturation, assimilation, immigration status, and stigmatization that result in discrimination in housing, banking, educational opportunities, and health disparities (Fisher et al., 1997). Another factor that may increase the complexity of understanding how and why various ethnic groups experience marginalization differentially is that second- and third-generation ethnic minority members often have quite different experiences associated with language acquisition, cultural assimilation, and social adjustment to dominant U.S. culture than do first-generation immigrants.

\section{GOODNESS-OF-FIT ETHICS (GFE) AND CO-LEARNING}

Fisher has called for investigators to approach research ethics with vulnerable populations within an ethics framework that conceptualizes participant respect and protections in terms of the goodness-of-fit among the specific research context and the unique characteristics of the participant population (Fisher, 2003a, 2003b; Fisher \& Masty, in press). Conceptualizing research risks and benefits as a product of both experimental design and participant attributes shifts judgments regarding ethical procedures away from an exclusive focus on assumed participant vulnerabilities to (a) an examination of those aspects of the research setting that are creating or exacerbating research vulnerability and (b) consideration of how the design and ethical procedures can be modified to best advance science and participant and social welfare.

The GFE framework is especially important in addressing institutional and scientific 
biases that often single out ethnic minority populations as posing "unique" and "difficult" ethical challenges, which can only be resolved by bending ethical requirements. For example, a situation of placing the burden of vulnerability on the participant population rather than the investigative procedures can emerge when developmental scientists argue that IRBs should permit waiver of parental permission for lowerincome minority populations because of the expected low permission rates. These requests are often based on the erroneous assumption that such populations are uncaring or lack the education to understand the value of the research (Fisher et al., 1997). The reality is that ethnic minority parents often refuse to permit their children to participate in research because they distrust the motives of the researchers, do not believe the research goals will benefit their communities, are fearful that the research will further stigmatize their children, or are concerned that confidentiality breaches will lead to unnecessary government intrusion (Fisher, 2002, 2004; Fisher \& Wallace, 2000).

\section{Correcting Ethnic Bias and Misperceptions}

The GFE framework for research with ethnic minority populations presents an opportunity to correct biases and misperceptions. The GFE model, like the multicultural competence model (Sue et al., 1998), assumes that adequate ethical decision making requires more than slight modifications to traditional ways of conducting science. It requires critical reflection about potential modifications in research goals and design, which can enhance scientific validity, participant protections, and social value. In order to apply the GFE model to studies involving waiver of parental permission, for example, the developmental scientist would be required to explore (a) which aspects of the research aims, designs, or recruitment procedures are "misfitted" to the values, fears, and hopes of the specific ethnic parent population and (b) how the design, aims, or recruitment procedures could be modified to produce a study that fit the requirements of populationsensitive science as well as methodologically sound science.

Research vulnerability as a relational concept. In the GFE model, research vulnerability is reduced when research procedures are fitted to participant characteristics (Fisher 2003a, 2003b, in press). In order to accomplish this, at the inception stage of research protocols, investigators should ask themselves the following questions: (a) What are the special life circumstances that render participants more susceptible to research risk? (b) Which aspects of the research design, implementation, or dissemination may create or exacerbate research risk? and (c) How can research and ethical procedures be fitted to participant characteristics to reduce vulnerability? (Fisher, 2003b; Fisher \& Masty, in press)

When research involves ethnic minority populations, life circumstances that increase participants' research vulnerability can include a combination of demographic characteristics such as language, education, minority and immigration status, disparities in health and health care opportunities, socioeconomic status, cultural assumptions about gender roles and attitudes toward authority, ethnic identity, and racial mistrust. In addition, other social or health risks may be layered on top of ethnic/cultural life circumstances, such as addiction, comorbid mental health disorders, illegal behavior, health risks (including diagnosed and undiagnosed conditions), social stigma, and membership in a violent social network. In order to establish the boundaries of GFE, such variables must be given careful consideration in toto rather than on a piecemeal basis. 


\section{GFE AND THE SCIENCE ESTABLISHMENT}

The traditional science establishment has endorsed a set of values by which investigators and the public can evaluate the responsible conduct of research. When embodied in federal regulations and professional codes of conduct, these largely Eurocentric, rationaldeductive, libertarian conceptions of the good (Prilleltensky, 1997) become moral premises that resist cultural challenges (Fisher, 1999). Chief among these is the utilitarian philosophy that the morally right action is the one that produces the most pleasing consequences (Mill, 1861/1957). Applied to ethicsin-science decision making, when a conflict between scientific rigor and participant welfare arises, the investigator's obligation to a small group of research participants may be superseded by her or his responsibility to produce reliable data that can potentially provide future benefits to members of society at large or to the participants' particular social group. Utilitarianism thus encourages a value structure in which potential benefits of science to society can receive higher moral priority than concrete and measurable risks to research participants.

Drawing on established works on research ethics (Beauchamp, Faden, Wallace, \& Walters, 1982; Freedman, 1975; Rosenwald, 1996; Veatch, 1987), Fisher (1999) identified a set of unchallenged assumptions based on traditional views of science:

- Knowledge gathering is a fundamental and unconditional good.

- Knowledge generated by the scientific method is and should be value free.

- Scientists are entitled to use humans as material for their pursuits.

- Respect, beneficence, and justice are guiding moral principles for ethical decision making in human subjects research.

- Cost-benefit analysis is an acceptable basis for deciding how to prioritize these moral principles and for guiding ethical decision making.

- Informed consent is the primary means of ensuring participants are not victims of an imbalance in favor of greater risks than benefits.

- The right to make autonomous decisions regarding research participation is dependent on the ability to weigh the risks and benefits of the experimental procedures.

- Principles of beneficence and justice can be subordinated to the principle of autonomy reflected in informed consent policies.

- The absence of harm justifies the absence of benefits if it leads to scientifically valid information.

- Science-in-ethics decision making is the province of those with professional authority, be it scientists, bioethicists, IRB members, or policy makers (Fisher, 1999, p. 36).

\section{Challenging Traditional Scientific Assumptions}

Investigator contact with the constantly shifting demographic landscape of the United States and the increasingly influential voice of ethnic minority scholars and participant communities is creating a sea change in traditional scientific value assumptions. As exemplified by the contributions to this volume, social and behavioral scientists increasingly acknowledge that the pursuit of knowledge is neither as personally value-free nor unaffected by external forces (such as the priorities of funders) as previous generations of scientists often assumed (see also Altman, 1995). The important gains that have been made within ethics-in-science decision making confirm that the reevaluation of the costs and benefits of conducting research is an ongoing process. For example, although costeffectiveness and cost-benefit analyses have merit in particular public health arenas (Haddix, Teutsch, \& Corso, 2002), their application is controversial when scholars 
and practitioners adopt an ultrautilitarian and noncontextualized stance (MacQueen, 2004; Pinkerton, Johnson, Masotti, Derse, \& Layde, 2002).

The GFE model moves multicultural ethics further by posing several interrelated questions about these value premises (Fisher, 1999; Greenfield, 1994; Markus \& Kitayama, 1991; Parham, 1993; Triandis, 1990): (a) Do the values embodied in current professional codes and federal regulations reflect the moral visions of different ethnocultural groups recruited for research participation? (b) Do scientists and participant groups have different conceptions of research risks and benefits? and (c) Is the value placed on the control and manipulation of variables compatible with the values, collectivity, and harmony characteristic of many ethnocultural populations?

To ensure the responsible conduct of research, these questions require that investigators give careful consideration to the different cultural lenses through which they and research participants view the ethics of research involving ethnic minority populations. Indeed, one of the important gains in multicultural research ethics is the movement toward incorporating participant perspectives in the evaluation of research risks and potential benefits (Cassell, 1982; Fisher, 2002, 2004; Fisher \& Wallace, 2000; Melton, Levine, Koocher, Rosenthal, \& Thompson, 1998). Co-learning is the GFE process through which participant perspectives are incorporated into the identification of ethical issues and construction of ethical procedures (Fisher, 1999, 2002).

\section{Co-Learning: The Process of Goodness-of-Fit Ethics}

The GFE model views scientist and participant alike as moral agents joined in partnership to construct ethical procedures that contribute to research designs reflecting social value and scientific validity as well as the principles of justice and care (Fisher, 1997, 1999, 2000). The GFE process of co-learning assumes that ethical decision making is deficient when it occurs in the absence of discourse illuminating the cultural lens through which the participant population views the research. Co-learning is grounded in the principle of respect. It assumes that both investigator and participant populations come to the research enterprise as experts: The investigator brings expertise about the scientific method and the extant empirical knowledge base, and prospective participants and their community representatives bring expertise about the fears and hopes toward, and value that they place on, the prospective research (Fisher, 1999, 2000).

Investigators can use co-learning procedures to share with prospective participants their views on how and why it is important to apply the scientific method to examine questions of societal import and to debates underlying areas of current ethical concern. In turn, the prospective participants, their families, and community representatives can apply their moral perspectives to critique the scientific and social value of a proposed study and share with investigators the value orientations guiding participant and community reactions to the planned procedures (Fisher, 1999, 2000; Fisher \& Wallace, 2000). When co-learning is soundly grounded and correctly implemented within a moral framework of respect, ethical procedures emerge that reflect a mutual accommodation to the values of science and the values of the cultural community in which the science will be conducted.

Similar in many ways to the principles underlying participatory research (MacQueen, 2004; Nichter, 1984; Weeks, Schensul, Williams, Singer, \& Grier, 1995), in the GFE process of co-learning, to be a stakeholder does not assume that scientists 
and participants share equally in the risk and benefits of research or that they share the same rights, status, and privileges. For example, investigators often have the benefit of more social capital than do participants in terms of education, wealth, and access to power and opportunities (Fisher, 1999, 2000). As stakeholders in a research protocol, however, investigators are dependent on research communities to fulfill recruitment goals and produce empirically valid knowledge of social value. Although research participants and the communities to which they belong may benefit from study participation, the nature of conducting research is such that the benefits that accrue to participants can rarely be measured using the same yardstick as that used to measure the benefits that accrue to investigators. Participant stakeholders may receive increased income through participant incentives, benefit from receiving current knowledge about the strengths or vulnerabilities of their population motivating the research, or increase their understanding of research methods (and thereby increase their ability to be better informed consumers of scientific reports as well as community advocates).

The experience of co-learning and mutual accommodation between investigators and participants as process for developing GFE is essential in multicultural research. Rather than compromise, co-learning is a dialectic that creates something new from stakeholders' participation in a relational process. Co-learning provides the essential knowledge base from which investigators can identify research methods and ethical procedures that fit the needs and values of the participant population. Even as scientists have a responsibility to produce research grounded within accepted scientific practice, they are also required—and ethically compelled-to protect participant autonomy and confidentiality. As a dialectic process, co-learning calls for the development of ethical procedures that facilitate and build on mutual accommodation in order to accomplish these goals. For example, when engaged in research among vulnerable populations of diverse cultural background, investigators must recognize that social norms regarding deference to authority often vary across ethnicity, generation, socioeconomic status, and assimilation status (Fisher, in press; Fisher \& Masty, in press; Kodish et al., 2004). Additionally, participants from multicultural backgrounds often must cope with language barriers, lack of experience in regard to asserting their rights within a clinical setting, and the perception that the delivery of future health care services is contingent on their research participation (Fisher et al., 2002; Fisher \& Masty, in press).

In the sections that follow, we describe a series of ethical challenges and solutions that exemplify the value of goodness-of-fit co-learning with minority and vulnerable populations in a resource-poor nation.

\section{ETHNOCULTURAL RESEARCH ETHICS IN THE DEVELOPING WORLD: TOURISM AND SEX WORK IN BELIZE}

Much of GFE has dealt with studies conducted in the United States, yet proactive engagement in GFE is equally crucial when social and behavioral scientists from developed countries conduct international research in less developed and/or resource-poor nations (Benatar \& Singer, 2000; Farmer, 1999, 2002). When international research involves official buy-in, approval, cooperation, or collaboration with national and local governmental agencies in host countries, consideration of the goodness-of-fit between Western research ethical practices and participant characteristics may require increased attention. Just as when scientists conduct studies in domestic settings, international 
researchers must be alert to the possibility that study findings may be used by governmental agencies to justify the implementation of social policies that further marginalize vulnerable populations. When conducting research among participants in developing countries, the "potentially exploitative nature of research" (Benatar \& Singer, 2000, p. 825) should be given careful consideration by investigators. In light of this caveat, the following examples are meant as illustrative rather than exhaustive. The examples are derived from concerns raised during a study conducted by Kathleen Ragsdale (the study's principal investigator $[\mathrm{PI}]$ and second author of this chapter) and Jessica Anders in Belize, Central America (Ragsdale \& Anders, 1998; Ragsdale \& Anders, 1999).

\section{Cultural and Economic Context of Sex Work in Belize}

Formerly known as British Honduras until it gained independence in 1981, Belize is a small multicultural and multiethnic country wedged between Mexico and Guatemala, yet has the longest barrier reef in the Western Hemisphere. Like many Caribbean and Central American countries faced with catastrophic economic restructuring and faltering agriculture and manufacturing export industries (Safa, 1995), Belizean national development strategies have focused on tourism as a way to pump dollars into its cash-poor economy (Mahler \& Wotkyns, 1993; SPEAR, 1993). Although tourism can bring in needed foreign currency to developing nations, it often differentially affects men and women due to the fact that "experiences with processes of economic growth, commercialization, and market expansion are determined by both gender and class" (Sen \& Grown, 1987, p. 25; see also Levy \& Lerch, 1991; McClaurin, 1996). Women working in the tourism sector often have fewer economic options than men. Economic opportunity for many poor women is restricted to low-skilled jobs in the tourism industry, such as domestic service or street vending (Richter, 1995). As is often the case in many Caribbean and Central American countries, the growth of tourism in Belize has also increased women's involvement in sex work as a way to meet their basic economic needs (Kane, 1993; Kempadoo, 1999; Ragsdale \& Anders, 1999). Although Belizean law does not prohibit sex work, it is illegal to operate a brothel in the country (U.S. Department of State, 2002); however, enforcement of this law is practically nonexistent. For example, one of the most well known brothels in the Belize City area operates openly on the main highway that connects the city and the international airport.

To investigate the nature and scope of sex work and tourism in Belize, Ragsdale and Anders conducted multimethod research in 1998 at three field sites in the following order: Belize City, Orange Walk Town, and Ambergris Caye. Due to time and budget constraints, the investigators conducted 1 month of intensive research at each site to gain a rapid assessment of conditions under which women engaged in sex work, as well as sex tourism's embeddedness within the tourism sector. The ethical challenges emerging at the three study sites will be used to illustrate GFE and co-learning as reflective and organic processes. In particular, we will describe ways in which conditions unique to each site caused the investigators to adapt different strategies appropriate for each site (Bernard, 1995; Fisher, 1999, 2002).

Case I. Voice of Community Members: Competing Frameworks in Belize City

There is increased awareness that giving the community voice is a vital key to GFE in research. Yet investigators who are not prepared for the reality of how rival discourses 
operate in multicultural settings may unexpectedly find themselves faced with negotiating the social terrain of competing groups who, in sincere attempts to ameliorate disparities, seek to push a particular agenda or claim proprietary rights to data (Fisher et al., 1997). In this section, we describe how Ragsdale and Anders arrived in Belize City to begin collecting data on the nature of tourism and the sex trade in Belize only to find that both governmental and nongovernmental organizations (NGOs) had particular agendas that they wanted the investigators to address.

Contacting key informants. As Belize City is the first destination for most tourists entering the country of Belize, Ragsdale and Anders began their research efforts by visiting various governmental agencies located in the city, including the Department of Women's Affairs, the Ministry of Health, and the Ministry of Justice. They also visited NGOs, including the Belize Organization for Women and Development (BOWAND), the Belize Family Life Association (BFLA), representatives of the Peace Corps, and the Society for the Promotion of Education and Research (SPEAR). Key informants from the community at large who had contact with tourists and/or brothel workers were also contacted, including volunteer workers, tourism operators, bar and club owners, taxi drivers, security guards, and police officers. Governmental, NGO, and community sources gave conflicting advice about the safety of entering brothels to conduct research. After weighing these reports, the investigators made plans to visit the most prominent brothel operating in the Belize City area; however, the wisdom of this decision was challenged a few days before the planned visit when the local newspaper reported that a client at the brothel had shot a security guard in the face. On receiving this news, the PI cancelled the trip, deciding that it was too dangerous for the investigators to enter the brothel.

Cultural stigma. Based on discussions with governmental, NGO, and community informants, the investigators confirmed that, as expected, there was much stigma associated with involvement in female sex work. In particular, at that time in Belize City there was a general perception that HIV/AIDS was a problem only among migrant sex workers and an associated assumption that limited health and research resourcessuch as represented by the presence of the investigators-should be directed toward more immediate concerns of permanent residents, such as domestic violence. Somewhat unexpectedly, the investigators also found that there was stigma attached to female investigators conducting research related to sex work. Among most key informants in Belize City, the investigation of sex work by female researchers was generally perceived as unusual-although in some cases it was deemed risqué or aberrant-when measured against traditional gender norms for Belizean women.

Confidentiality. Through discussions with contacts in the Belize City, the investigators also learned that issues of confidentiality are exacerbated in this small and resourcepoor country. For example, Belize has an estimated population of 250,000 (U.S. Department of State, 2002), and therefore the inhabitants of this small nation generally distrust claims of truly anonymous testing. The potential for stigmatization associated with being HIV-positive inhibits and delays HIV testing for many Belizeans and nonBelizeans who would otherwise like to know their HIV status. This is especially true for migrant women engaged in sex work in the country, for, although sex work is legal, the stigmatizing perception that female sex workers (FSWs) are carriers of sexually 
transmitted infections can deter such women from HIV testing.

Lessons learned. A primary lesson learned during this phase of the research is that investigators working in international settings must be able to fit not only ethical procedures but the research questions and methods as in-country conditions dictate. Ragsdale and Anders initially planned to spend approximately 2 weeks in Belize City making contact with key gatekeepers among governmental agencies, NGOs, and community members in order to gain an overall impression of the current state of tourism and sex work in Belize. The investigators then planned to travel directly from Belize City to the tourist destination of Ambergris Caye to conduct the primary part of the research project; however, during discussions among key informants in Belize City, the investigators learned that a considerable number of brothels operated openly in Orange Walk Town, which was located 66 miles from Belize City. According to several sources, the brothels serviced the local community as well as truck drivers and tourists on their way to Mexico. During this process, the investigators also discovered that freelance sex work (Kempadoo, 2001), commonly referred to as "streetwalking," was practically nonexistent in Belize. Although the investigators heard anecdotal reports of a handful of discrete escort services frequented by local businessmen and wealthier tourists, sex work is primarily conducted on brothel premises.

The multisourced co-learning consultations described above highlighted obstacles to brothel recruitment and study implementation embodied in community suspicions, intergroup conflict surrounding the goals of the research, and stigma associated with the investigators' gender. Ragsdale and Anders spent an extra 2 weeks in unsuccessful attempts to gain access to brothels in Belize
City. During those 2 weeks, it became increasingly clear that the investigators would have to sacrifice time spent at another site in order to build the community connections necessary to overcome the barriers of entering Belize City brothels. Yet Ragsdale and Anders were realistic in their evaluation that increased rapport building might not guarantee access to any brothel within the vicinity of the city. Therefore, rather than risk spending limited research time on recruitment efforts that might not prove productive, the investigators decided to move to a more promising site of data collection. As mentioned earlier, Ragsdale and Anders had initially decided that Ambergris Caye would be their second and final field site; however, after their consultations with key informants in Belize City, they felt compelled to investigate Orange Walk Town's potential as a field site before traveling on to Ambergris Caye.

\section{Case 2. Vulnerable Populations \\ and Research Challenges: Brothel \\ Sex Workers in Orange Walk Town}

The second phase of the pilot study was conducted among brothel-based FSWs in Orange Walk Town, Belize. The town was of particular interest because of Orange Walk's geographic location on a major highway that connects Belize City to Chetemal, Mexico. This transportation corridor brings longhaul truckers and tourists through the town, which had approximately 10 brothels in operation at the time of the study. In the following example, we use the investigators' experiences to illustrate how they identified circumstances of particular vulnerability for a sample of FSWs voluntarily engaged in sexual labor in Orange Walk Town.

Nature of the problem. With the advent of the HIV/AIDS pandemic in the 1980s, much biomedical and behavioral research that focused on women involved in sex work 
reinforced negative stereotypes by implicating FSWs in the heterosexual transmission of HIV while downplaying the role of clients and domestic partners in unsafe sexual practices (Farmer, 1999; Vanwesenbeeck, 2001). In addition, the focus on HIV transmission associated with female sexual labor overshadowed more contextualized examinations of the economic, social, and health risks faced by impoverished women engaged in voluntary sex work. For example, many FSWs are the sole economic provider for their children, aging parents, or younger siblings, yet fear the loss of community respect and/or family support should the source of their remittances be discovered (Ragsdale \& Anders, 1998, 1999). Consequently, impoverished FSWs often seek to safeguard their anonymity by migrating to foreign host countries in order to decrease the likelihood that their engagement in sex work will be reported back to members of their home communities. While continuing to support their dependents, migrant FSWs are physically and emotionally separated from their communities and families. As a further safeguard, migrant FSWs often purposefully distance themselves from social interactions with those who live in the host communities in which they work.

International migration can place FSWsespecially undocumented workers-in conditions where they are vulnerable to coercion by immigration officials, police, pimps, brothel owners, and clients in the host country. Vulnerability can be further increased when migrant FSWs have little education and/or do not speak the language of the host country. The social invisibility of women engaged in sexual labor, such as the migrant brothel-based sex workers discussed in this example, can also affect their vulnerability, even as it makes such hidden populations difficult to locate, access, and recruit to participate in studies (Singer, 1999). Yet the paucity of holistically grounded research on the socioeconomic conditions faced by FSWs increases the difficulty of developing socially responsive policies that facilitate the delivery of services and foster advocacy for impoverished women and their children. Although it is critical to address global issues of sexual trafficking (Butcher, 2003), it is also important for researchers and policy makers to be aware that even among women who "voluntarily" engage in sex work, "the lines between autonomy and coercion [are] neither rigid nor always easily discernible" (Kempadoo, 2001, p. 53).

Research overview. In Orange Walk Town, the investigators verbally administered a face-to-face semistructured survey to 33 brothel workers who were legal migrants from the adjacent countries of El Salvador, Guatemala, and Honduras (Ragsdale \& Anders, 1999). Participant responses, although not audiotape-recorded, were recorded as close to verbatim as possible on each survey. The Institutional Review Board of the University of Florida approved the consent procedures, which included informing participants of the sexually sensitive nature of the research, their right to refuse to answer any question, and their right to terminate the interview at any time. All participants lived on brothel premises, and the interviews were conducted on-site at each brothel. The majority of participants planned to return to their home country in the near future (less than 1 year from the date of the interview). The Orange Walk brothels accessible to the investigators employed between one and eight FSWs at the time of the study. It was from this prospective sample of 35 women that Ragsdale and Anders ultimately recruited 34 respondents. One prospective participant, the only Belizean national in the study, declined to be interviewed on the grounds that she served drinks but did not engage in sex work. Another participant had to terminate her interview shortly after it began when 
one of her regular clients arrived unexpectedly at the brothel. Therefore, the final sample of 33 women represented approximately $73 \%$ of the estimated 45 brothel-based FSWs in Orange Walk Town.

Ethical challenges to transnational research. Working in the developing world can present unexpected challenges when conducting research among vulnerable populations. In the town of Orange Walk, potential obstacles the investigators faced included unanticipated language barriers, the possibility of coerced participation from FSWs by brothel owners on behalf of governmental health officials, having to use a guide/interpreter appointed by the minister of health, inability to access participants off brothel premises in order to conduct interviews, personal safety issues while on brothel premises, and data safety monitoring. These potential obstacles are discussed in further detail below.

Language barriers and governmentappointed interpreters. Although the official language of Belize is English, the investigators discovered that monolingual Spanish speakers predominated among the local Orange Walk population, including the migrant brothel workers in the sample. Although Anders was completely bilingual, Ragsdale's more limited Spanish language abilities required her to conduct interviews with the participants using the services of an interpreter. Through NGO contacts made while in Belize City, Ragsdale and Anders located an Orange Walk-based volunteer HIV-prevention worker fluent in Spanish to act as an interpreter; however, following a meeting in Belize City, the country's minister of health appointed a Ministry of Health worker to be the official interpreter for the investigators. The Ministry of Health worker was an HIV outreach worker whose responsibilities included visiting Orange Walk Town brothels to educate FSWs on safer sex (including correct and consistent condom use) and other sexual health issues. He was comfortable and articulate discussing sexually sensitive topics, yet had no enforcement obligations or reporting duties associated with his position as a Ministry of Health worker. Thus, not only did he know most of the brothel owners and FSWs, but there was no risk that he would disclose to authorities personal information disclosed during the course of recruitment.

The investigators had reservations, however, about accepting the "offer" of an interpreter, based on the appointee's status as a Ministry of Health worker. As the meeting with the minister of health proceeded, it became clear that declining the offered services would have meant canceling the project in Orange Walk Town, with the strong implication that Ragsdale and Anders could be barred from conducting research elsewhere in the country. The investigators speculated that this tactic was a maneuver to gain a measure of surveillance over the researchers' data collection activities. They also speculated that this tactic was a way to ensure the personal safety of the investigators while on brothel premises in order to avoid the possibility of an incident that could have negative political ramifications for the country. The ethical dilemma of conducting research using a Ministry of Healthappointed interpreter, as opposed to one freely chosen by the investigators, was further complicated by the fact that the appointed interpreter was male. When conducting sexually sensitive research, it has become standard practice that field staff and participants be matched according to relevant sociodemographic characteristics, such as language and gender. That Anders was fluent in Spanish and female had a positive effect on rapport building and information exchange between the researcher and her interviewees; however, on their arrival in Orange Walk, Ragsdale and Anders quickly became aware 
that the Ministry of Health-appointed interpreter was an excellent gatekeeper, as he was well-known among the local FSWs and brothel owners in his capacity as a HIVprevention outreach worker. The health worker became the liaison between the brothel owners and the investigators and was instrumental in facilitating the cooperation of the owners in allowing the investigators to access the brothels.

In his role as an HIV-prevention outreach worker, the health worker was also a skilled and experienced facilitator of discussions related to sexually sensitive topics. He was on a friendly basis with the participants, who displayed no discomfort discussing sex work-related issues within his presence. The cheerful banter between the health worker and the participants attenuated-but did not dismiss - the asymmetrical power dynamics between the research investigators, the interpreter, and the participants. The health worker proved to play an indispensable role as the gatekeeper between the brothel owners and the investigators, as well as between the participants and the investigators. He was also an excellent key informant who facilitated the investigators' understanding of brothel system organization in Orange Walk Town. Because he was a known and trusted entity, Ragsdale and Anders had access to 8 of the estimated 10 brothels operating in the town. The high level of success in accessing brothels in Orange Walk Town stood in sharp contrast to the investigators' unsuccessful efforts to safely access brothel premises in Belize City. Unaccompanied by a gatekeeper, the investigators were unable to gain permission from any Belize City brothel owner to gain access to brothel premises in order to recruit potential participants who engaged in female sex work. The researchers also found that the stigma of conducting an investigation among sex workers was markedly reduced in Orange Walk. The reasons for this may have been two-fold: (a) the Ministry of Health worker's role as gatekeeper added legitimacy to the investigators' presence on brothel premises, which was suspect on the grounds that they were non-Belizean, female researchers and (b) the investigators lived with a well-respected host family within the Orange Walk Town community, a senior member of which was a local health care provider.

Coercion. The investigators carefully considered the multiple issues of potential coercion in this particular setting. For example, after having approved a study, governmental officials in some countries may pressure brothel owners to cooperate. In turn, brothel owners may pressure brothel workers to participate. This was not the case in Belize. Ragsdale and Anders accompanied the health worker when he initially approached the brothel owners, who displayed no concern in response to the request to interview FSWs. This is probably due to the fact that sex work is legal in Belize and the health worker had no direct authority over the brothels; however, this raised the issue of monitoring the safety of sensitive data, a concern the investigators faced near the end of the study, which will be addressed below.

A related ethical concern faced by the investigators was whether conducting interviews on the premises would be perceived as coercive by the participants. Contrary to Ragsdale and Anders's expectations, discussions with the participants indicated that they perceived their involvement in sex work to be voluntary and the brothel environment to be relatively noncoercive. For example, unlike standard practices in more coercive brothel systems (Cwikel, Ilan, \& Chudakov, 2003; Reed 2001), participants in Orange Walk Town could refuse sex with any client at their own discretion, a right that the participants stated they exercised regularly. In another example of how the Orange Walk Town brothel system deviated from more 
coercive brothel environments, the participants were able to limit the amount and kind of sex activity in which they engaged with clients. In fact, most participants stated that they limited their engagement in sex work to one or two clients per night. Participants also reported that their duenos (brothel owners) did not retain their passports as a punitive or coercive measure to control the movement of the brothel workers. In fact, participants were free to move from brothel to brothel at will, and several respondents reported that they had worked at three or more different brothels in Orange Walk Town. The lack of an overtly coercive brothel environment was pivotal to Ragsdale and Anders's decision that it was ethically feasible to conduct the interviews on-site.

A third ethical concern was how to appropriately demonstrate the investigators' appreciation of the time participants gave the interview. Budget constraints did not allow for monetary compensation to participants. Therefore, the process of co-learning was used to guide the investigators' selection of nail polish as a culturally appropriate token of appreciation for the respondents. The young women who took part in the study did not have easy access to these types of "extras." Participants received a gift of several bottles of nail polish and appreciated the opportunity to choose their own favorites among several color options. In the process of co-learning, the investigators also were informed by participants that taking part in the study had helped to alleviate the intense boredom associated with brothel life.

Confidentiality and data monitoring. Fitting confidentiality procedures to the culture of small or closed communities is particularly challenging in international settings (Fisher et al., 2002; Simons \& Williams, 1999). In small developing countries, anonymity may be difficult to maintain, and the consequences of disclosure or participant identification may raise serious safety issues. A breach of confidentiality can damage reputations and the social networks on which participants and their families may depend. For example, it is quite common for persons living in small countries to know many fellow inhabitants personally, by reputation, or through kin, social, and political networks. Therefore, many FSWs migrate to foreign countries, not only to earn more but to ensure their anonymity. For Ragsdale and Anders's population, the risk of a breach of confidentiality was low because the migrant sex workers did not generally interact with the local population. Through co-learning, the investigators identified that although the participants reported occasional local clients, their primary clients were transient long-haul truckers traveling the route from Belize City to the border of Mexico.

To safeguard the study population's anonymity, the investigators were careful not to approach participants in public venues, but only on brothel premises. Although participants did not perceive that there was a high level of stigmatization associated with sexual labor in Orange Walk, they stated that they personally felt ashamed of their involvement in sex work and, therefore, rarely left brothel premises. As mentioned earlier, participants said they were not restricted to brothel premises, as evidenced by their ability to relocate from brothel to brothel; yet they did not often frequent the shops in Orange Walk.

Following informed consent describing the nature of the study and their rights as subjects of research, the participants were administered a semistructured survey in Spanish. The nature of the survey was such that there was no risk that the Ministry of Health appointee, in his dual role as Ragsdale's mandated interpreter and a governmental health worker, would discover information he otherwise would not have known, which might place the brothel 
workers at risk; however, it is important to consider the potential ramifications regarding confidentiality if the participants had been members of the host community rather than members of a migratory, transnational population that was not well integrated into community life. For example, how might this status difference have affected the issue of confidentiality posed by the mandated use of the health worker to conduct sexually sensitive research in a place were anonymity is difficult to maintain? According to the respondents, participants who migrated for the purpose of sex work believed that moving to Belize was one way to ensure that their involvement in female sex work remained unknown in their home countries.

Although such theoretical considerations are important, the investigators were faced with a far less theoretical dilemma after receiving a surprise announcement. Near the end of the data collection phase, Ragsdale and Anders were informed that highly placed governmental officials had made a unilateral decision that the Ministry of Health had proprietary rights to the survey data. This incident highlighted the fact that investigators who seek to contribute to knowledge about problems faced by stigmatized populations must be aware that the generation and dissemination of knowledge is not always valuefree when addressing socially sensitive or emotionally charged issues (Fisher, 2002; Fisher \& Wallace, 2000). The investigators decided that it was ethically untenable to turn over the primary data. They chose not to respond to the request and, inexplicably, were not asked to do so again; however, in her role as PI, Ragsdale had the surveys and informed consents carried out of the country by a trusted person as a further safeguard to ensure that the data would not be confiscated at a future date.

Research in populations of low literacy. According to Benatar and Singer (2000), pivotal to the performance of ethically grounded research is "obtaining meaningful informed consent in the subjects' home tongue and with an understanding of their world view or value system" (p. 825). The participants in Orange Walk Town were administered informed consent in Spanish, which included informing respondents of their right to refuse to answer any question and to terminate the interview at any time. Ragsdale's interpreter initially tried to rush through the consent process. The PI was adamant that each prospective respondent be fully informed of her rights as a participant, and the Ministry of Health interpreter complied. As stated earlier, two prospective participants exercised their right to terminate the survey.

As Fisher and Wallace (2000) emphasize, "face validity is crucial if communities are to accept social policy proposals based on research" (p. 106). Engagement in co-learning is an important procedure to assure face validity. Through the process of co-learning, Ragsdale and Anders discovered they had to clarify or substitute particular survey terminology to assure the survey questions were appropriate to the population. Such modifications were tied not simply to Englishto-Spanish translation but to the unique colloquialisms of the brothel workers. For example, most Orange Walk Town participants were unfamiliar with the Spanish medical term sexo vaginal (vaginal sex), which they referred to in lay language as sexo normal (normal sex). A goodness-of-fit approach also sensitized the investigators to language that might be insulting or distressful among already stigmatized or marginalized participants (Fisher, 2002). Sensitive to the historical misuse of stigmatizing language to pathologize women who engage in sex work as aberrant, Ragsdale and Anders adjusted the survey term sex worker to be more reflective of the participants' worldview. Although most participants did not 
find the unfamiliar term trabajadora del sexo (sex worker) offensive, they referred to themselves as muchachas (girls). Ragsdale and Anders adopted their use of the term muchacha as a sign of respect during all interactions and in subsequent publications (Ragsdale \& Anders, 1998, 1999). Although a seemingly small linguistic change, the use of this term was an important signifier to the participants that the investigators did not view the women as aberrant. In the process of co-learning, the investigators also identified that (in contrast to much of the literature on women engaged in sexual labor) no participant referred to herself or a coworker as a prostituta (prostitute). In fact, participants described this term as nearly as offensive and derogatory as the slang term puta (whore).

Case 3. Participants as Experts:

Locals and Tourists on Ambergris Caye

Ambergris Caye, Belize, was a town of particular interest to Ragsdale and Anders because of its social geography. The barrier reef offshore the resort island is one of the primary venues used to attract international tourists to Belize. The investigators had anticipated that, due to its prominence as a tourist attraction, Ambergris Caye would also have a brothel system in place as is typical of similar resort areas throughout the Caribbean (Kempadoo, 1995).

Contacting key informants. After arriving on Ambergris Caye, the investigators sought to make contact with governmental, NGO, and health care providers; however, due to the island's small population, as well as its proximity to Belize City (via water taxi or airplane), the investigators found that such resources were not readily available. Instead, Ragsdale and Anders spoke with community representatives, including tour operators, hotel owners, bartenders, taxi drivers, boat captains, business owners, hotel and restaurant workers, other local residents, and tourists. These key informants noted that brothel work was not typical on the island. Through firsthand observation, the investigators confirmed that the well-established brothel system that existed in Orange Walk Town did not operate on Ambergris Caye. For example, there was only one bar operating on the caye that employed a single FSW.

During this period of initial discovery, the investigators also found that their status as researchers was not recognized by key informants in the manner in which it had been in Orange Walk Town. Most residents of Ambergris Caye initially viewed the investigators as another pair of single tourist women visiting the small resort island rather than researchers exploring the connections between tourism and sex work in Belize. Therefore, the investigators again had to adjust their methods of data collection in order to accommodate the local conditions at the new field site of Ambergris Caye.

Ethical challenges to inquiry as research conditions change. Based on the unexpected discovery that there was not a population of sex workers from which to draw a sample, Ragsdale and Anders evaluated the feasibility of developing a new survey to explore the nature of sexual interactions between tourist and local populations on the island. The option of developing a new survey was dismissed as unfeasible given (a) the research time frame of 1 month at the site, (b) the expense and/or limited access to necessary technology available on the island to develop a new survey and consent form for IRB submission (such as exorbitant user fees for computers and international phone service), and (c) the time constraints involved for IRB approval after a new consent form had been developed and submitted to the University of Florida. Given these very real constraints, Ragsdale and Anders decided to use their limited time at the field site to conduct 
preliminary interviews and make observations that would become the basis for later research questions. Drawing on ethnographic models of knowledge elicitation (Bernard, 1995; LeCompte \& Schensul, 1999), Ragsdale and Anders were able to build rapport with locals and tourists to obtain a holistic snapshot of the complexity of sexual exchanges between the inhabitants of Ambergris Caye and the tourists who migrated to the island to take advantage of its sun, sand, barrier reef, and other amenities.

Co-learning and community perspectives. The multimethod approach adopted by Ragsdale and Anders fit well into the normative life on the small island, where friendly and informal social relationships are prized. Many of the permanent residents on the caye quickly came to know that the investigators were there to conduct preliminary data collection on the nature of sex exchanges between local and tourist populations and were happy to assist by contributing their observations. The investigators, however, found that most informants felt the process of conducting formal interviews was cold, artificial, and unfriendly; and therefore, informants resisted this method of data collection. Local residents would not only poke good-natured jokes at the researchers when they appeared with their notebooks but would fail to arrive for scheduled interviews. As a way to adjust to local conditions and assimilate more appropriately into the culture on Ambergris Caye, Ragsdale and Anders began to appear without their notebooks. Instead, the investigators brought paper and pen tucked into their pockets for more unobtrusive note taking, which informants found acceptable. The investigators found that rich and descriptive conversations often ensued when they would informally stop by to "hangout and chat" with an informant at his or her place of employment or home. Ragsdale and Anders often shared meals and conversation with locals who became friends and acquaintances, and the investigators began to be assimilated into normal work activities, such as helping to "collect the door" at live band performances, rolling silverware with a waitress, folding brochures for a dive shop owner, watching a jewelry shop for a friend, and looking after small children. In order to access the more transient population of tourists constantly arriving and leaving, Ragsdale and Anders made observations and contact with male and female tourists at bars, restaurants, and nightclubs. They struck up conversations with tourists at these venues, as well as on the beachfront and other venues regularly frequented by tourists on Ambergris Caye.

Co-learning as an avenue to research questions. As stated earlier, Ragsdale and Anders conducted preliminary research on Ambergris Caye based on a month of intensive interactions with locals and tourists on the island, far too short a time to make any hard-andfast research conclusions. Rather, during the time spent on the caye, the investigators were able to make an important conclusion: There was little evidence that either organized sex tourism such as exists in Southeast Asia (Troung, 1990) or the organized brothel systems that exist in some Caribbean countries (Kempadoo, 1995) was established in Belize at the time of the study. Due to the lack of a population of brothel workers to whom the survey could be administered, the time spent on Ambergris Caye became a preliminary exploration of potential questions of research. Through observation, dialogue, and elicitation among permanent residents on the island (locals) and transient populations (tourists), Ragsdale and Anders were able to establish that tourists often engaged in sexual risk behavior with fellow tourists and local residents on Ambergris Caye (Ragsdale, 2000). This finding provided the groundwork for research conducted by 
Ragsdale on the sexual risk behavior of single female tourists while on vacation in Costa Rica (Ragsdale, 2002).

\section{GOODNESS-OF-FIT ETHICS: DYNAMICS OF DOING GOOD WELL}

The GFE model holds that respectful relationships among investigators, prospective participants, and the community at large are instrumental to fulfilling the obligation to conduct scientifically valid and responsible research that serves to protect participant rights and welfare. In this final section, we discuss the GFE model applied to an understanding of investigator-participant power relationships.

\section{Reframing the Discourse of Power}

Goodness-of-fit ethics recognizes that, although power asymmetry is intrinsic to most research involving human subjects, relationship power is a fluid commodity that is constantly negotiated and renegotiated (Fisher, 1997, 1999).

Those who seek greater symmetry in power relationships emphasize that each party must derive something out of the relationship and be able to exercise discretionary control over the resources prized by the other (Goodin, 1985). However, these resources must be used to enhance, not compromise, the ethical and scientific integrity of experimentation. (Fisher, 1999, p. 45)

A cornerstone of the GFE model calls for "investigators engaged in the critical task of generating the information on which ... services, public opinion, and policies ... will be based" to actively engage themselves in the "formidable responsibility of ensuring that their procedures are scientifically sound, culturally valid, and morally just" (Fisher et al., 2002, p. 1025). This may not be an easy task, as scientists can be unwilling or unable to actively engage in the difficult and personally challenging self-reflection necessary to lay an ethics-in-science foundation conducive to co-learning (Fisher, 2000). In turn, co-learning requires that investigators, who have often spent years training to become recognized as experts in a particular field of study or discipline, actively reframe discourses of power and hierarchy that may have afforded them special or privileged status, as investigators seek to achieve a more inclusive research environment.

The exercise of inclusion, especially when the needs and desires of community members do not easily fit into an investigator's research agenda, calls for vigilance to assure participant sensitive research. Although the dynamic nature of conducting human subjects research does not lend itself to "cookie cutter" solutions to sound ethics-in-science practices (Fisher, 2004; see also Hoagwood, Jensen, \& Fisher, 1996), the goal of achieving GFE when designing and implementing research among vulnerable populations is attainable. Fisher and Wallace (2000) recommended several steps for achieving GFE to enhance problem identification through co-learning activities, such as focus groups. These include (a) creating an equitable environment in which all participants are encouraged to explore the multifaceted aspects of the topic under discussion, (b) interpretation of the discourse in a manner that recognizes the dynamic nature of ethical deliberation within individual participants and the multiplicity of views among participants, and (c) a determined effort to avoid simplistic interpretations of participant views (e.g., a procedure is either right or wrong). Applying this approach allows for "in-depth analysis of individual perspectives that can challenge current ways of thinking about ethics-in-science 
issues and point to new directions of moral awareness and scientific inquiry" (Fisher \& Wallace, 2000, p. 102).

\section{Goodness-of-Fit Ethics and Multicultural Research}

Members of ethnic minority or otherwise marginalized communities are often understandably skeptical about the presumed benefits and/or merit of policydriven research based on past personal experience and observation as well as historical misuse of scientific findings. The call for investigators to be proactively engaged in GFE will increase the identification of best practices in human subjects research as it simultaneously acts to increase trust of research among ethnic minority communities and their members.
The development and evaluation of culturally appropriate co-learning procedures to ensure goodness-of-fit in the ethical conduct of social and behavioral research is a dynamic and ongoing process. Although there is a growing body of qualitative research on ethics-in-science decision making involving ethnic minority populations, the transferability of such knowledge is less well understood. The aim of goodness-of-fit inquiry is not to document participant perspectives that can or should dictate specific research designs or ethical practices in other ethnic minority populations. Rather the purpose is to provide models of ethical procedures reflective of specific participant group perspectives that can challenge current ways of thinking about ethics-in-science issues and point to new directions of moral awareness and scientific inquiry for multicultural research.

\section{REFERENCES}

Altman, D. G. (1995). Sustaining interventions in community systems: On the relationship between researchers and communities. Health Psychology, 14, 526-536.

Beauchamp, T. L., Faden, R. R., Wallace, R. J., \& Walters, L. (1982). Introduction. In T. L. Beauchamp, R. R. Faden, R. J. Wallace, \& L. Walters (Eds.), Ethical issues in social science research (pp. 3-39). Baltimore: Johns Hopkins University Press.

Benatar, S. R., \& Singer, P. A. (2000, September 30). A new look at international research ethics. BMJ 2000, 321, 824-826.

Bernard, H. R. (1995). Research methods in anthropology: Qualitative and quantitative approaches (2nd ed.). Walnut Creek, CA: AltaMira.

Butcher, K. (2003). Confusion between prostitution and sex trafficking. Lancet, 361(1973), 1983.

Cassell, J. (1982). Does risk-benefit analysis apply to moral evaluation of social research? In T. L. Beauchamp, R. R. Faden, R. J. Wallace, \& L. Walters (Eds.), Ethical issues in social science research (pp. 144-162). Baltimore: Johns Hopkins University Press.

Chun, K. (1995). The myth of Asian American success and its educational ramifications. In D. Nakanishi \& T. Nishida (Eds.), The Asian American educational experience (pp. 95-112). New York: Routledge.

Cwikel, J., Ilan, K., \& Chudakov, B. (2003). Women brothel workers and occupational health risks. Journal of Epidemiology and Community Health, 57, 809-15. 
Demo, D. H., \& Hughes, M. (1990). Socialization and racial identity among Black Americans. Social Psychology Quarterly, 53, 364-374.

Diallo, K. (2003). My heart will cross this ocean: My story, my son, Amadou. New York: One World/Ballantine.

Dublin, T. (1996). Becoming American, becoming ethnic: College students explore their roots. Philadelphia: Temple University Press.

Eller, J. D. (1999). From culture to ethnicity to conflict: An anthropological perspective on international ethnic conflict. Ann Arbor: University of Michigan Press.

Essed, P. (1991). Understanding everyday racism: An interdisciplinary theory. Newbury Park, CA: Sage.

Farmer, P. (1999). Infections and inequalities: The modern plagues. Berkeley: University of California Press.

Farmer, P. (2002). Can transnational research be ethical in the developing world? Lancet, 360(9342), 1266.

Fisher, C. B. (1997). A relational perspective on ethics-in-science decision making for research with vulnerable populations. IRB: Review of Human Subjects Research, 19, 1-4.

Fisher, C. B. (1999). Relational ethics and research with vulnerable populations. Reports on research involving persons with mental disorders that may affect decision-making capacity (Vol. 2, pp. 29-49). Commissioned Papers by the National Bioethics Advisory Commission, Rockville, MD.

Fisher, C. B. (2000). Relational ethics in psychological research: One feminist's journey. In M. Brabeck (Ed.), Practicing feminist ethics in psychology (pp. 125-142). Washington, DC: APA.

Fisher, C. B. (2002). Participant consultation: Ethical insights into parental permission and confidentiality procedures for policy relevant research with youth. In R. M. Lerner, F. Jacobs, \& D. Wertlieb (Eds.), Handbook of applied developmental science (Vol. 4, pp. 371-396). Thousand Oaks, CA: Sage.

Fisher, C. B. (2003a). A goodness-of-fit ethic for informed consent to research involving persons with mental retardation and developmental disabilities. Mental Retardation and Developmental Disabilities Research Reviews, 9, 27-31.

Fisher, C. B. (2003b). A goodness-of-fit ethic for child assent to non-beneficial research. American Journal of Bioethics, 3(4), 27-28.

Fisher, C. B. (2004). Ethics in drug abuse and related HIV risk research. Applied Developmental Science, 8, 90-102.

Fisher, C. B. (2005). Commentary: SES, ethnicity and goodness-of-fit in clinicianparent communication during pediatric cancer trials. Journal of Pediatric Psychology, 30(3), 231-234.

Fisher, C. B., Hoagwood, K., Boyce, C., Duster, T., Frank, D.A., Grisso, T., et al. (2002). Research ethics for mental health science involving ethnic minority children and youths. American Psychologist, 57, 1024-1040.

Fisher, C. B., Jackson, J., \& Villarruel, F. (1997). The study of African American and Latin American children and youth. In W. Damon (Series Ed.) \& R. M. Lerner (Vol. Ed.), Handbook of child psychology: Vol. 1. Theoretical models of human development (5th ed., pp. 1145-1207). New York: Wiley.

Fisher, C. B., \& Masty, J. K. (in press). A goodness-of-fit ethic for informed consent to pediatric cancer research. In R. T. Brown (Ed.), Handbook of pediatric psychosocial oncology. New York: Oxford University Press. 
Fisher, C. B., \& Wallace, S. A. (2000). Through the community looking glass: Re-evaluating the ethical and policy implications of research on adolescent risk and psychopathology. Ethics \& Behavior, 10, 99-118.

Fisher, C. B., \& Wallace, S. A., \& Fenton, R. E. (2000). Discrimination distress during adolescence. Journal of Youth and Adolescence, 29, 679-695.

Freedman, B. (1975). A moral theory of informed consent. Hastings Center Report, $5,32-39$.

Gaertner, S. L., \& Dovidio, J. F. (1986). Prejudice, discrimination, and racism. Orlando, FL: Academic.

Goodin, R. E. (1985). Protecting the vulnerable. Chicago: University of Chicago Press.

Greenfield, P. M. (1994). Independence and interdependence as developmental scripts: Implications for theory, research, and practice. In P. M. Greenfield \& R. R. Cocking (Eds.), Cross-cultural roots of minority child development (pp. 1-37). Hillsdale, NJ: Lawrence Erlbaum.

Gould, S. J. (1981). The mismeasure of man. New York: W. W. Norton.

Haddix, A. C., Teutsch, S. M., \& Corso, P. S. (Eds.). (2002). Prevention effectiveness: A guide to decision analysis and economic evaluation (2nd ed.). New York: Oxford University Press.

Hoagwood, K., Jensen, P. S., \& Fisher, C. B. (1996). Towards a science of scientific ethics in research on child and adolescent mental disorders. In K. Hoagwood, P. Jensen, \& C. B. Fisher (Eds.), Ethical issues in research with children and adolescents with mental disorders (pp. 3-14). Hillsdale, NJ: Lawrence Erlbaum.

Kane, S. C. (1993). Prostitution and the military: Planning AIDS intervention in Belize. Social Science \& Medicine, 36(7), 965-979.

Kempadoo, K. (1995). Prostitution, marginality and empowerment: Caribbean women in the sex trade. Paper presented at the International Workshop, Women on the Threshold of the XXI Century, University of Havana, Cuba.

Kempadoo, K. (Ed.). (1999). Sun, sex, and gold: Tourism and sex work in the Caribbean. Boulder, CO: Rowman \& Littlefield.

Kempadoo, K. (2001). Freelancers, temporary wives, and beach-boys: Researching sex work in the Caribbean. Feminist Review, 67, 39-62.

Kodish, E., Eder, M., Noll, R. B., Ruccione, K., Lange, B., Angiolillo, A., et al. (2004). Communication of randomization in childhood leukemia trials. Journal of the American Medical Association, 291, 470-475.

LeCompte, M. D., \& Schensul, J. J. (1999). Analyzing and interpreting ethnographic data. Walnut Creek, CA: AltaMira.

Levy, D. E., \& Lerch, P. B. (1991). Tourism as a factor in development: Implications for gender and work in Barbados. Gender \& Society, 5(1), 67-85.

Lowe, L. (1996). Immigrant acts: On Asian American cultural politics. Durham, NC: Duke University Press.

MacQueen, K. (2004). Bioethics and anthropology: A call for partnership. Retrieved December 2, 2004, from www.medanthro.net/stand/overview/index.html

Mahler, R., \& Wotkyns, S. (1993). Belize: A natural destination (2nd ed.). Santa Fe, NM: John Muir.

Markus, H. R., \& Kitayama, S. (1991). Culture and the self: Implications for cognition, emotion, and motivation. Psychological Review, 98(2), 224-253.

Mathabane, M. (1990). Kaffir boy in America. New York: Free Press.

McClaurin, I. (1996). Women of Belize: Gender and change in Central America. New Brunswick, NJ: Rutgers University Press. 
Melton, G. B., Levine, R. J., Koocher, G. P., Rosenthal, R., \& Thompson, W. C. (1988). Community consultation in socially sensitive research: Lessons from clinical trials of treatments for AIDS. American Psychologist, 43, 573-581.

Mill, J. S. (1957/1861). Utilitarianism. New York: Bobbs-Merrill.

Nichter, M. A. (1984). Project community diagnosis: Participatory research as a first step toward community involvement in primary health care. Social Science and Medicine, 19(3), 237-252.

Ogbaa, K. (2003). The Nigerian Americans (the new Americans). New York: Greenwood.

Parham, T. A. (1993). White researchers conducting multicultural counseling research: Can their efforts be "mo betta"? Counseling Psychologist, 21, 250-256.

Pinkerton, S. D., Johnson-Masotti, A. P., Derse, A., \& Layde, P. M. (2002). Ethical issues in cost-effectiveness analysis. Evaluation and Program Planning, 25, 71-83.

Portes, A., \& Stepick, A. (1993). City on the edge: The social transformation of Miami. Berkeley: University of California Press.

Prilleltensky, I. (1997). Values, assumptions, and practices: Assessing the moral implications of psychological discourse and action. American Psychologist, 52, 517-535.

Ragsdale, K. (2000). Don't leave home without it: Tourist women, sexual risk and condom use. Paper presented at the Annual Meeting of the Society for Applied Anthropology, San Francisco, CA.

Ragsdale, K. (2002). Tourist women balancing temptation and HIV risk in Costa Rica. Gainesville: University of Florida.

Ragsdale, K. (in press). Ethnocentrism. In Y. Jackson (Ed.), Encyclopedia of multicultural psychology. Thousand Oaks, CA: Sage.

Reed, K. D. (2001). A tale of two cities: Brothel-based female commercial sex work, spread of HIV, and related sexual health care interventions in India, using Bombay and Delhi as examples. Journal of Family Planning and Reproductive Health Care, 27, 223-227.

Richter, L. K. (1995). Gender and race: Neglected variables in tourism research. In R. Butler \& D. G. Pearce (Eds.), Change in tourism: People, places, processes. London: Routledge, pp. 71-91.

Rosenwald, C. G. (1996). Making whole: Method and ethics in mainstream and narrative psychology. In R. Josselson (Ed.), Ethics and process in the narrative study of lives (Vol. 4, pp. 245-273). Thousand Oaks, CA: Sage.

Safa, H. I. (1995). The myth of the male breadwinner: Women and industrialization in the Caribbean. Boulder, CO: Westview.

Sen, G., \& Grown, C. (1987). Development, crises, and alternative visions: Third World women's perspectives. New York: Monthly Review Press.

Simon, R. I., \& Williams, I. C. (1999, November). Maintaining treatment boundaries in small communities and rural areas. Psychiatric Services 50, 1440-1446. Retrieved March 18, 2005, from http://ps.psychiatryonline.org/cgi/content/ full/50/11/1440

Singer, M. (1999). Studying hidden populations. In J. J. Schensul, M. D. LeCompte, R. T. Trotter, E. K. Cromley, \& M. Singer (Eds.), Mapping social networks, spatial data, and hidden populations (pp. 125-191). Thousand Oaks, CA: AltaMira.

SPEAR. (1993). SPEAReports 9, Globalization and Development: Challenges and Prospects for Belize. Belize: Author. 
Stepick, A., \& Foner, N. (1998). Pride against prejudice: Haitians in the U.S. Boston: Allyn \& Bacon.

Stepick, A., Grenier, G., Castro, M., \& Dunn, M. (2003). This land is our land: Immigrants and power in Miami. Berkeley: University of California Press.

Sue, D. W., Carter, R. T., Casas, J. M., Fouad, N. A., Ivey, A. E., Jensen, M., et al. (1998). Multicultural counseling competences: Individual and organizational development. Thousand Oaks, CA: Sage.

Triandis, H. C. (1990). Cross-cultural studies of individualism and collectivism. In J. Berman (Ed.), Nebraska Symposium on Motivation, 1989 (pp. 41-133). Lincoln: University of Nebraska Press.

Troung, T. D. (1990). Sex, money and morality: The political economy of prostitution and tourism in South East Asia. London: Zed Books.

U.S. Department of State. (2004). Country reports on human rights practices: Belize. Washington, DC: Department of State. Retrieved March 21, 2005, from www.state.gov/g/ drl/rls/hrrpt/2004/41749.htm

Vanwesenbeeck, I. (2001). Another decade of social scientific work on sex work: A review of research 1990-2000. Annual Review of Sex Research, 12, 242-89.

Veatch, R. M. (1987). The patient as partner. Bloomington: Indiana University Press.

Weeks, M. R., Schensul, J. J., Williams, S. S., Singer, M., \& Grier, M. (1995). AIDS prevention for African-American and Latina women: Building culturally and gender-appropriate intervention. AIDS Education and Prevention, 7(3), 251-263. 
01-Trimble-4708.qxd 5/9/2005 6:51 PM Page 26 